\title{
Diagnosis of Atypical Molluscum Contagiosum: The Utility of a Squash Preparation
}

\author{
Lydia I. Eleftheriou, BS; Sarah C. Kerr, MD; and Erik J. Stratman, MD.
}

A

4-year-old boy was referred to the outpatient dermatology clinic for two growths on his scalp. The first lesion had been present on the vertex scalp for six months and was asymptomatic except for recent inflammation and drainage of white exudate. A second growth developed on the patient's posterior parietal scalp in recent weeks and reportedly resembled the original appearance of the initial lesion. Review of systems was negative, and the parents denied any affected close contacts. There had been no intervention to the lesions. On examination, the vertex of the scalp revealed a $0.3 \mathrm{~cm}$ hemorrhagic crusted papule with surrounding desquamation and minimal surrounding erythema. The left posterior parietal scalp had a $0.2 \mathrm{~cm}$
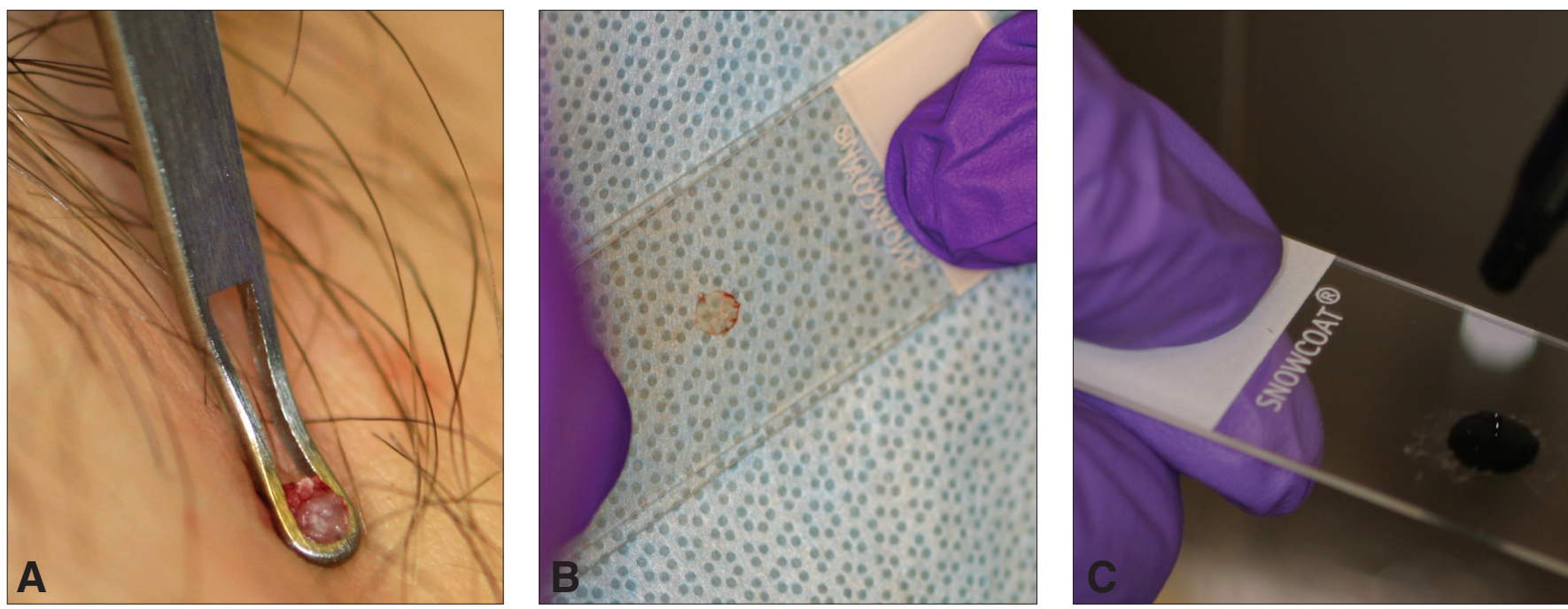

Figure 1: (A) After incision with a 19-gauge needle, a comedone extractor is used to express the molluscum cheesy core. (B) The molluscum core is squashed between two glass microscope slides. (C) The squashed molluscum core is stained using 5 to 7 drops of Giemsa stain.

Author Affiliations:

Lydia I. Eleftheriou, BS*†; Sarah C. Kerr, MD†; Erik J. Stratman, MD†

*University of Minnesota Medical School-Twin Cities, Minneapolis, MN tDepartment of Dermatology, Marshfield Clinic, Marshfield, Wisconsin, USA

\section{Corresponding Author:}

Erik J. Stratman, MD

Marshfield Clinic/St. Joseph's Hospital

Department of Dermatology

1000 North Oak Avenue

Marshfield, WI 54449

Tel: 7I5-387-53। I

Fax: 7|5-389-4|4|

Email: stratman.erik@marshfieldclinic.org
Keywords: Molluscum contagiosum;

Cytology; Giemsa; Molluscipoxvirus

Received: July 15, 2010

Revised: September 13, 2010

Accepted: September 22, 2010

doi: $10.3121 / \mathrm{cmr} .2010 .953$

The Aperture, like the opening in the lens of a microscope that allows light to pass through, is a forum for art, humor, and images that provides a portal for new or different views of medicine and research. 
smooth pearly papule. The remainder of the examination was unremarkable. The skin overlying the parietal scalp lesion was incised using a 19-gauge needle. A white, cheesy central core was removed with a comedone extractor (figure 1A). The specimen was then squashed with firm pressure between two glass microscope slides (figure 1B). The top slide was discarded, and the material on the bottom slide was stained with $3 \mathrm{ml}$ of Giemsa stain (figure 1C). The slide was then gently rinsed with tap water. A single drop of mineral oil was applied to the air-dried specimen, followed by placement of a coverslip over the specimen. The slide was then viewed with light microscopy (figure 2). Cytologic examination revealed uniform, discrete and clustered purple ovals consistent with the large cytoplasmic viral inclusions of Molluscipoxvirus (Henderson-Paterson bodies), thus confirming the diagnosis of molluscum contagiosum (MC). As this was the only intact lesion on the full body exam of the child, the removal and squash preparation of the lesion's contents was not only diagnostic, but therapeutic as well. No further treatment was required.

\section{Discussion}

Molluscum contagiosum (MC) is a self-limited epidermal infection caused by the Molluscipoxvirus. It accounts for approximately $1 \%$ of all dermatologic diagnoses. The virus can be transmitted by infected fomites, casual or sexual contact, and self-inoculation, with a predilection for children, sexually active, or immunocompromised individuals. Molluscum lesions can affect any region of the body and typically present as asymptomatic $1 \mathrm{~mm}$ to $5 \mathrm{~mm}$ pearly, white or skin-colored round papules with an umbilicated center. Morphologic variants of MC are common and include giant lesions greater than $5 \mathrm{~mm}$, eczematous lesions, and folliculocentric lesions with secondary abscess formation. These atypical presentations can closely mimic other dermatologic conditions, including lymphangioma, condyloma acuminatum, and basal cell carcinoma, and can be diagnostically challenging, especially in human immunodeficiency virus type-1 (HIV-I) positive individuals. These patients tend to form giant molluscum plaques and verrucous lesions. ${ }^{1}$ Immunocompetent patients can form uncharacteristic lesions due to hair follicle involvement and variable states of inflammation, including secondary abscess formation. ${ }^{2,3}$ Diagnosis of $\mathrm{MC}$ is generally made by clinical evaluation; however, a more definitive diagnosis can be obtained with biopsy or cytology. The presence of uniform, acidophilic, Henderson-Paterson bodies is pathognomonic for MC. ${ }^{4}$ Biopsy could be performed to determine the diagnosis, but this technique is more costly, invasive, and takes more time than in-office squash preparation. In this case we described the technique and utility of squash preparation using Giemsa stain for in-office diagnosis of mulluscum contagiosum. In addition to Giemsa, other staining techniques such as Wright, 10\% potassium hydroxide, Gram and Papanicolaou have been described in literature. .,6,7,8 $^{-1}$

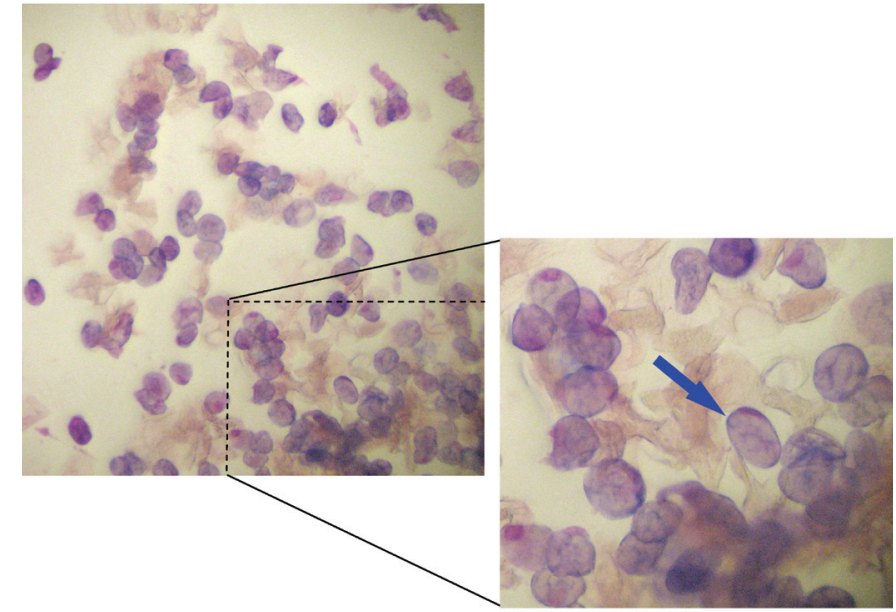

Figure 2: Discrete and clustered purple ovals consistent with large cytoplasmic viral inclusions of Molluscipoxvirus (Henderson-Paterson bodies), magnification x20. Inset: Magnified view of Henderson-Paterson body (arrow).

\section{Conclusion}

The squash preparation and cytologic identification of Henderson-Paterson bodies is an efficient method for rapid diagnosis of clinically challenging cases of molluscum contagiosum.

\section{References}

1. Smith KJ, Yeager J, Skelton H. Molluscum contagiosum: its clinical, histopathologic, and immunohistochemical spectrum. Int J Dermatol 1999;38:664-672.

2. Brown J, Janniger CK, Schwartz RA, Silverberg NB. Childhood molluscum contagiosum. Int J Dermatol 2006;45:93-99.

3. Ive FA. Follicular molluscum contagiosum. Br J Dermatol 1985;113:493-495.

4. Frenkl T, Potts J. Infections and Inflammation: Sexually Transmitted Infections-Molluscum Contagiosum. In: Wein AJ, ed. Campbell-Walsh Urology. 9th ed. Maryland Heights, MO: WB Saunders; 2007. Ch. 11.

5. Bauer JH, Miller OF, Peckham SJ. Medical Pearl: confirming the diagnosis of molluscum contagiosum using $10 \%$ potassium hydroxide. J Am Acad Dermatol. 2007;56:S104-105.

6. American Academy of Pediatrics. Summaries of Infectious Diseases. In: Pickering LK, Baker CJ, Kimberlin DW, Long SS, eds. Red Book: 2009 Report of the Committee on Infectious Diseases. 28th ed. Elk Grove Village, IL: American Academy of Pediatrics; 2009: 466.

7. Penneys NS, Matsuo S, Mogollon R. The identification of molluscum infection of immunohistochemical means. J Cutan Pathol 1986;13:97-101.

8. Thompson CH, Biggs IM, DeZwart-Steffe RT. Detection of molluscum contagiosum virus DNA by in-situ hybridization. Pathology 1990;22:181-186. 